\title{
War against respiratory syncytial virus
}

\author{
An 8-year experience at a tertiary hospital
}

Adel S. Al Harbi, MD

\begin{abstract}
الأهداف: تقييم معدل الإصابة بعدوى الفيروس التنفسي

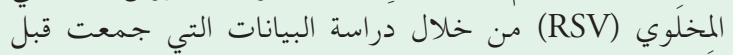

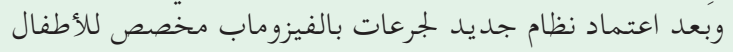
السعوديين ذوو المخاطر العالية.

الطريقة: أقيمت دراسة بأثر رجعي في مدينة الأمير سلطان

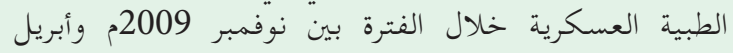

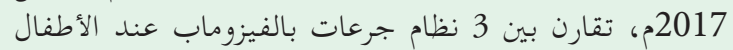

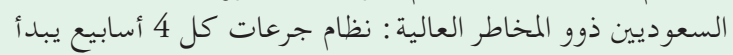

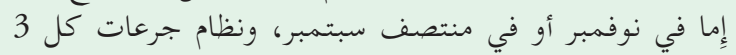
أسابيع يبدأ في منتصفي سيتف سنمبر.

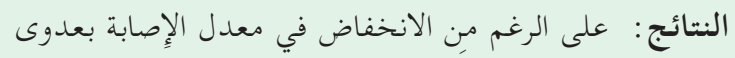

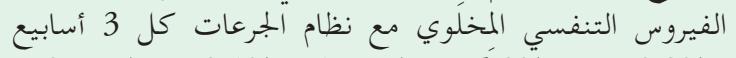

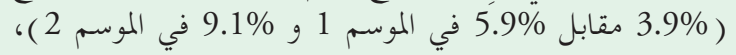

ولم تظهر فروق ذات دلالة إِحصائية بين أنظمة الجرعات الثلاث.

الحاتمة: التوسع في استخدام باليفيزوماب عند الأطفال حديثي

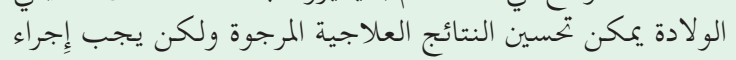

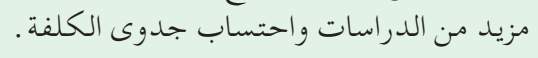

Objectives: To assess the respiratory syncytial virus (RSV) infection incidence rate through the analysis of data collected before and after implementation of a new palivizumab dosing regimen customized for a high-risk Saudi population.

Methods: This was a retrospective cohort study performed at Prince Sultan Military Medical City, Riyadh, Saudi Arabia between November 2009 and April 2017 on 1704 high risk Saudi young children and comparing 3 palivizumab regimens: a 4-week interval dosing regimen starting in either November or mid-September and a 3-week interval dosing regimen starting in mid-September.
Results: Despite a decrease in the incidence rate of RSV infection with the three-week interval regimen $(3.9 \%$ versus $5.9 \%$ in seasons 1 and $9.1 \%$ in seasons 2 ), we did not find significant differences among the 3 groups.

Conclusion: Expanded use of palivizumab in newborn children could improve outcomes, but further investigation and a careful cost analysis are required.

Saudi Med J 2018; Vol. 39 (12): 1200-1206 doi: $10.15537 /$ smj.2018.12.23355

From the Department of Pediatric Pulmonary Medicine, Prince Sultan Military Medical City, Riyadh, Kingdom of Saudi Arabia.

Received 17th July 2018. Accepted 24th October 2018.

Address correspondence and reprint request to: Dr. Adel S. Al Harbi, Prince Sultan Military Medical City, Riyadh, Kingdom of Saudi Arabia.Email:dr.adelalharbi@gmail.com ORCID ID: orcid.org/0000-0001-7974-4026

$\mathrm{R}$ espiratory syncytial virus (RSV) is the most common cause of infants acute lower respiratory tract infections (LRTIs) and a major cause of admission to hospital. ${ }^{1,2}$ Consequently, limitation of RSV infection spread has become a public health priority. ${ }^{3,4}$ A meta-analysis, funded by the World Health Organization (WHO), using data from systematic reviews published between 2005 and 2010 revealed that globally 33.8 (95\%CI: 19.3-46.2) million new cases of RSV-associated acute LRTIs occurred in young children (less than 5 years old), with more than 3.4 million episodes necessitating hospitalization. The incidence of RSV infection in developing countries is higher than that in industrialized countries, accounting for the double according to some resources. ${ }^{1}$ Children younger than 2 years of age have the highest risk of RSV infection with a rate going up to $83 \%{ }^{5}$ with a peak in the first year of life. ${ }^{6}$ 
In addition, emerging data suggest that severe RSV-related LRTIs during childhood increase the risk of subsequent wheezing or asthma later in life. ${ }^{7}$ In Saudi Arabia, a study performed during a 3-year period (April 1993-March 1996) on Saudi children showed that $79 \%$ of the children admitted to King Khalid University Hospital (KKUH) with an acute respiratory tract infection were diagnosed with RSV infection. ${ }^{8}$

Bronchiolitis or viral pneumonia is the primary manifestation of RSV infection. ${ }^{9}$ According to the American Academy of Pediatrics (AAP) guidelines, ${ }^{10}$ management of bronchiolitis is based mainly on respiratory support and hydration in the inpatient setting. Considering the paucity of therapeutic alternatives, it is essential to understand existing challenges in the development of preventive options for RSV infection.

Respiratory syncytial virus outbreaks of epidemic levels occur yearly at predictable times. A review of RSV infections in the Middle East region ${ }^{11}$ shows that, similar to other parts of the world, RSV infections occurring the winter and peak around January, with the same age groups affected. However, differences from one country to another might exist; a more precise understanding of the timing of annual RSV epidemics should assist healthcare providers in maximizing the benefit of preventive therapies.

At present, there are no marketed vaccines against RSV infection. Palivizumab, a humanized murine monoclonal antibody that targets the virus fusion protein, is the main pharmacologic agent active in preventing RSV infection. ${ }^{12}$ Palivizumab immunoprophylaxis has been shown to be effective in the prevention of hospitalization in high-risk populations. ${ }^{13-15}$ The impact-RSV study demonstrated that monthly intramuscular administration of palivizumab to premature infants and infants with chronic lung disease throughout the RSV season resulted in a $55 \%$ reduction in hospitalizations due to RSV compared with infants receiving placebo $(4.8 \%$ versus $10.6 \% ; p<0.001) .{ }^{16}$ Subsequent analyses of palivizumab utilization have been used to identify populations that

Disclosure. The author has no conflict of interests, and the work was not supported or funded by any drug company. Dr. Adel S. Al Harbi is a member of the Editorial Team, and was therefore excluded from any final editorial decisions regarding this paper. benefit from palivizumab immunoprophylaxis. These populations of interest are primarily children born prematurely ${ }^{17-20}$ and those with chronic lung disease ${ }^{17,19}$ or congenital heart disease. ${ }^{21,22}$

Over the years, we noticed at Prince Sultan Military Medical City (PSMMC), Riyadh, Saudi Arabia pediatric unit that RSV infection was a major cause of admission for young children, and fatal outcome was observed in many cases. Although occasional reports on the prevention of RSV infection in young Saudi infants have appeared in the literature, a local prevention plan customized to the Saudi population plan has not been studied. Therefore, over the past 8 years, we examined and studied Saudi infants with a high risk of severe illness from RSV to determine the best preventive actions in order to reduce hospitalization rates. We implemented a new palivizumab dosing regimen and created a specialized prophylaxis center. The aim of this paper was to evaluate the incidence of RSV infection before and after the implementation of new palivizumab administration criteria, thus assessing its efficacy and laying out a prevention plan to be considered for reducing the occurrence and burden of RSV infection.

Methods. The methodology of elaborating the prevention plan was 2-fold: the retrospective assessment of a new palivizumab administration regimen through the analysis of data collected over 8 years (November 2009 to April 2017) and the creation of a prophylaxis center facilitating collaboration between healthcare professionals and patients.

At a single healthcare system, the PSMMC, the author analyzed around 8 years (November 2009 to April 2017) of surveillance data for LRTIs and RSV infections in young Saudi children at high risk of getting an RSV infection to evaluate the best administration schedule and dose of palivizumab. Ethical approval was obtained from the PSMMC Research Ethics Committee and run in accordance with the principles of the Helsinki Declaration and in compliance with local laws and regulations.

The inclusion criteria were young children at high risk for RSV infection, according to the AAP guidelines, for candidates for RSV prophylaxis with palivizumab: children $(\leq 2$ years $)$ with bronchopulmonary dysplasia, infants with a history of premature birth ( $\leq 35$ weeks gestational age), and children ( $\leq 2$ years) with hemodynamically significant congenital heart disease. Exclusion criteria were 1) otherwise healthy infants with less than 37 weeks gestational age, 2) otherwise healthy children aged more than 2 years of age. 
The primary goal was to compare the number of RSV infections based on 1) the number and frequency of palivizumab injections received and 2) the starting date for prophylaxis. The secondary objective was to describe the high-risk population for RSV infection in Saudi Arabia. Recruitment was based on referral from different pediatric units; emergency room (ER), pediatric intensive care unit (PICU), neonatal intensive care unit (NICU) and outpatient clinics, to the centralized RSV prophylaxis center according to the shared eligibility criteria. All included infants received a prophylactic injection of palivizumab. The injection scheme applied during the first year of the study conformed to the product labeling and available data for RSV seasonality in Saudi Arabia. Meaning, that the first dose was administered in November and repeated every 4 weeks until March. In the second season of the study, the first injection was administered earlier in mid-September, and the remaining shots were administered every 4 weeks until March. In the remaining seasons, injections started in mid-September but were administered at a 3-week interval. The young subjects were followed throughout the RSV season, any LRTIs were treated, and virus detection was performed. Disposable mucus extractors were used to collect samples for detection. Samples were transported to the laboratory according to the manufacturer's instructions and tested for common respiratory viruses: RSV, influenza types A and B, parainfluenza types 1, 2 or 3 and adenoviruses. A detailed epidemiological questionnaire, which included infant characteristics (gestational age, birth date, birth weight, and so forth), perinatal history, clinical presentation, medical history, risk factors for respiratory illnesses, and family demographics, was completed by the treating physician.

Prophylaxis center. Prince Sultan Military Medical City is a tertiary care center serving the military and Ministry of Defense and a referral center for 27 secondary care hospitals all over Saudi Arabia. Therefore, this hospital is serving over 6 millions Saudi patients where $50 \%$ are children. Disease management programs are structured care packages for patients with a specified disease aiming at improving the quality and reducing the cost of care. ${ }^{23}$ For RSV infections, the core of disease management is prevention. In 2001, we created an RSV prophylaxis center at PSMMC aiming to overcome the challenges of an appropriate prevention plan: lack of awareness and administrative procedures. The staff included pediatric pulmonologists, neonatologists, infectious disease physicians, nurses, and coordinators. Awareness campaigns in collaboration with the different hospital units and distributed RSV memos including simplified AAP guidelines for palivizumab-eligible patients were conducted. A referral form (Figure 1) for eligible patients and circulated it to all pediatricians, NICU, and pediatric ER staff were created. In terms of management, the coordinator facilitates communication between healthcare professionals and patients; nurses prepare dosing injections in advance to save time.

Statistical analysis. Data entry and data analysis were performed using Statistical Package for the Social Sciences (SPSS) version 23.0 (IBM Corporation, Armonk, NY, USA). The summary statistics for quantitative variables included the mean, standard deviation, median, minimum, and maximum. Those for qualitative variables included the number and percentage of patients in frequency tables. Participant characteristics included gender, age, age group, gestational age, and the number of doses of palivizumab. The 95\% confidence intervals were estimated for the proportions or incidence rates of relevant outcomes (incidence rate of RSV). Pearson's Chi-square $\left(\chi^{2}\right)$ and Fisher's exact tests were used to compare categorical variables. For continuous normally distributed data, student's t-test and analysis of variance were used to compare means between 2 or more groups. The MannWhitney $U$ and Kruskal-Wallis tests were used if the data failed the assumption of normality, which was checked graphically or using the Shapiro-Wilk test. Statistical significance was indicated by $p<0.05$.

Results. The study included 1704 participants with a mean age of $5.2 \pm 7.2$ months and $58 \%$ were males. Approximately $11.4 \%$ had bronchopulmonary dysplasia (BPD), and $11.5 \%$ had chronic heart disease (CHD), the major 2 inclusion comorbidities. Approximately $70 \%$ were born prematurely, and the mean gestational age at birth was $30.7 \pm 4.6$ weeks (Table 1 ).

The overall incidence rate of RSV infection fluctuated significantly across the seasons (Table 2): it was significantly higher in the 2010-2011 season than in the 2012-2013 season, and significantly higher in the 2011-2012 season than in the 2012-2013 and 2015-2016 seasons.

Children older than 2 years had a significantly lower RSV incidence rate than all the other age groups (Table 3). Furthermore, the association between RSV positivity and major participant characteristics (Table 4) revealed that participants with an RSV infection were significantly older (7.4 months compared to 4.9 months, $p=0.001$ ) and predominantly male $(p=0.016)$. Bronchopulmonary dysplasia comorbidity was more frequently found among RSV-positive patients (17\%) than among RSV-negative patients (10.9\%). 
Season year $2017 / 2018$

$\frac{\text { Respiratory Syncytial Virus (RSV) Prophylaxis Program }}{\text { Referral Form }}$

Parts $A \& B$ to be completed by the referring physician and returned by email: email of the coordinator

Contact info of the coordinator (EXTENSION)

\begin{tabular}{|c|c|c|c|c|c|c|}
\hline \multicolumn{7}{|c|}{ (A) PATIENT INFORMATION } \\
\hline Patient's Name & & & & \multicolumn{3}{|c|}{ MRN } \\
\hline \multirow{2}{*}{$\begin{array}{l}\text { Patient's Date } \\
\text { of Birth }\end{array}$} & \multirow{2}{*}{\multicolumn{3}{|c|}{ 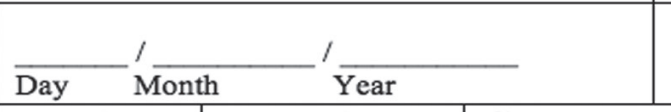 }} & \multirow[t]{2}{*}{ Gestational Age } & \multirow{2}{*}{\multicolumn{2}{|c|}{-}} \\
\hline & & & & & & \\
\hline Gender & $\square$ MALE & $\square$ FEMALE & Contact No. & & & \\
\hline \multicolumn{4}{|c|}{ Referring Team/Physician } & Bleep & Ext & \\
\hline \multicolumn{7}{|c|}{ (B) CRITERIA FOR PROPHYLAXIS } \\
\hline \multicolumn{7}{|c|}{$\begin{array}{l}\square \text { Born at } \mathbf{2 8} \text { weeks gestation or earlier and aged } \leq \mathbf{1 2} \text { months at the start of or during the local RSV season } \\
\text { (after Oct. } 1, \text { Year) }\end{array}$} \\
\hline
\end{tabular}

$\square$ Born at 33-35 weeks gestation and aged $\leq 6$ months (born after May 1, Year) at the start of or during the local RSV season with two or more risk factors:

$\square$ Child care attendance

$\square$ School-aged siblings

$\square$ Exposure to environmental air pollutants

$\square$ Congenital abnormalities of the airways

$\square$ Severe neuromuscular disease

$\square$ Children aged $<24$ months (born after Oct. 1, Year) with bronchopulmonary dysplasia/chronic lung disease (BPD/CLD) and who required oxygen and/or medical therapy within the 6 months preceding the RSV season

Diagnosis Treatment

$\square$ Children aged $<24$ months who require daily respiratory treatments for conditions that adversely affect respiratory function, such neuromuscular conditions and GE reflux disease with recurrent aspiration

$\square$ Children aged<24 months (born after Oct. 1, Year) with hemodynamically significant congenital heart disease Diagnosis Treatment

$\square$ Children aged $<\mathbf{1 2}$ months (born after Oct. 1, Year) with congenital heart disease who receive medication to control congestive heart failure, moderate to severe pulmonary hypertension, or cyanotic heart disease

(C) RSV Immunoprophylaxis Doses (This part to be completed by the RSV Team)

- Please enter the patient's current body weight in kilograms and the date of injection in the appropriate boxes below. Complete only the boxes for the current injection request.

\begin{tabular}{|l|l|l|l|l|l|l|}
\hline $\begin{array}{l}\text { Date of Injection } \\
\# 1:\end{array}$ & $\begin{array}{l}\text { Date of Injection } \\
\# 2:\end{array}$ & $\begin{array}{l}\text { Date of Injection } \\
\# 3:\end{array}$ & $\begin{array}{l}\text { Date of Injection } \\
\# 4:\end{array}$ & $\begin{array}{l}\text { Date of } \\
\text { Injection \#5: }\end{array}$ & $\begin{array}{l}\text { Date of } \\
\text { Injection \#6: }\end{array}$ & $\begin{array}{l}\text { Date of } \\
\text { Injection } \\
\# 7:\end{array}$ \\
\hline Body weight $(\mathrm{kg})$ & Body weight (kg) & Body weight (kg) & Body weight (kg) & $\begin{array}{l}\text { Body weight } \\
(\mathrm{kg})\end{array}$ & $\begin{array}{l}\text { Body weight } \\
(\mathrm{kg})\end{array}$ & $\begin{array}{l}\text { Body } \\
\text { weight } \\
(\mathrm{kg})\end{array}$ \\
\hline DOSE (mg) & DOSE (mg) & DOSE (mg) & DOSE (mg) & DOSE (mg) & DOSE (mg) & $\begin{array}{l}\text { DOSE } \\
(\mathrm{mg})\end{array}$ \\
\hline Doctor signature & Doctor signature & Doctor signature & Doctor signature & $\begin{array}{l}\text { Doctor } \\
\text { signature }\end{array}$ & $\begin{array}{l}\text { Doctor } \\
\text { signature }\end{array}$ \\
\hline
\end{tabular}

Figure 1 - Referral form for palivizumab administration. 
When comparing RSV positivity with the number of injections received, bivariate analysis showed that participants with an RSV infection received fewer doses of palivizumab (3.1 doses compared to 3.7 doses for those without an RSV infection) (Table 4).

Regarding the comparison of the 3 different palivizumab dosing regimens, we noticed that the incidence of RSV infection was reduced to approximately half $(3.9 \%)$ in the last season with the new regimen (start in mid-September and q3 weeks injections) compared with the first 2 seasons $(5.9 \%$ in seasons 1 and $9.1 \%$ in season 2) (Table 2). However, there were no significant differences among the 3 groups considered in the study (Table 5).

Discussion. This report documents the first time that such an approach has been initiated in the field of RSV infection prophylaxis. Changes in the dosage and timing of palivizumab administration according to the local RSV season could improve outcomes. This conclusion was supported by the larger eduction in RSV incidence with the new dosing regimen. However, several limitations of this study must be noted: based on the epidemiology of RSV and the Saudi population, the number of participants $(n=1704)$ in this study was sufficient to obtain solid conclusions; however, it was a single-center study, and a multicenter trial is essential to generalize the results and extrapolate values at a national level. In addition, the study involved expert experience and opinion and did not adopt a structured clinical trial design, which limits the interpretation of the results. A clearly planned protocol with written informed consent from participants and a long-term follow up would have strengthened the study. Furthermore, the hospitalization rate and infection severity were not assessed, representing further limitations of the study. The formation of a prophylaxis program center is an important step in preventing the spread of RSV infection. The increase in awareness and organizational improvement may have positively influenced the study results since the center was inaugurated in the second season of the study.

The epidemiological results of this study in Saudi Arabia were in line with those in the international literature. ${ }^{24}$ The population at the highest risk of RSV infection is male children under 2 years of age. The most common comorbidity in RSV-infected children was BPD.

The lower number of palivizumab dose administered to RSV-infected patients could indicate that prophylaxis with palivizumab is dose dependent. Nevertheless, the difference was not significant, so further investigations are required to confirm this hypothesis. Moreover, considering the relatively high price of palivizumab, a cost-effectiveness analysis is essential to prove the benefit of additional doses for patients and healthcare systems.

Although the incidence rate of RSV infection

Table 1 - Characteristics of 1704 young children at high risk for respiratory syncytial virus..

\begin{tabular}{lrc}
\hline Characteristics & $\mathbf{n}$ & $(\%)$ \\
\hline Gender & & \\
Male & 991 & $(58.2)$ \\
Female & 702 & $(41.2)$ \\
Missing data & 11 & $(0.6)$ \\
Age in months (mean \pm SD) & 5.2 & \pm 7.2 \\
Number of palivizumab doses & & \\
1 & 194 & $(11.4)$ \\
2 & 167 & $(9.8)$ \\
3 & 198 & $(11.6)$ \\
4 & 219 & $(12.9)$ \\
5 & 271 & $(15.9)$ \\
6 & 123 & $(7.2)$ \\
7 & 98 & $(5.8)$ \\
8 & 6 & $(0.4)$ \\
Comorbidities & & \\
BPD & 195 & $(11.4)$ \\
CHD & 196 & $(11.5)$ \\
CLD & 42 & $(2.5)$ \\
Prematurity & 1187 & $(69.7)$ \\
Gestational age in weeks & 30.7 & \pm 4.6 \\
(mean \pm SD) & & \\
\hline BPD - bronchopulmonary dysplasia, CHD - chronic heart disease, & \\
\hline & CLD - chronic lung disease & \\
\hline
\end{tabular}

Table 2 - Incidence rate of respiratory syncytial virus infection across seasons.

\begin{tabular}{lc}
\hline Seasons & Incidence rate $(95 \% \mathrm{CI})$ \\
\hline $2009-2010$ & $5.9 \%(2.3-9.50)$ \\
$2010-2011$ & $9.1 \%(4.7-13.4)$ \\
$2011-2012$ & $9.3 \%(6.3-12.2)$ \\
$2012-2013$ & $3.0 \%(1.3-4.8)$ \\
$2013-2014$ & not available \\
$2014-2015$ & $4.6 \%(1.9-7.3)$ \\
$2015-2016$ & $3.9 \%(1.2-6.6)$ \\
\hline
\end{tabular}

Table 3 - Respiratory syncytial virus incidence rate per age group.

\begin{tabular}{lcl}
\hline Age group (months) & \multicolumn{2}{c}{ Incidence rate $(95 \% \mathrm{CI})$} \\
\hline $0-6$ & $4.1 \%$ & $(2.9-5.3)$ \\
$7-12$ & $8.5 \%$ & $(5.4-11.9)$ \\
$13-18$ & $9.7 \%$ & $(4.6-14.8)$ \\
$19-24$ & $12.7 \%$ & $(3.6-21.8)$ \\
$>24$ & $0.7 \%$ & $(0.0-2.2)$ \\
\hline
\end{tabular}


Table 4- Association between respiratory syncytial virus positivity and major participant characteristics.

\begin{tabular}{lccc}
\hline & RSV positivity $(\mathrm{N}=89)$ & RSV negativity $(\mathrm{N}=1615)$ & $P$-value \\
\hline Number of palivizumab doses (mean \pm SD) & $3.1 \pm 1.6$ & $3.7 \pm 1.8$ & 0.03 \\
Age in months (mean \pm SD) & $7.4 \pm 7.0$ & $4.9 \pm 7.1$ & 0.001 \\
Gender (\%) & & & \\
Male & $63(70.0)$ & $928(57.5)$ & 0.016 \\
Female & $26(29.2)$ & $676(41.8)$ & 0.18 \\
CHD (\%) & $13(14.6)$ & $183(11.3)$ & 0.04 \\
BPD & $15(16.8)$ & $180(11.1)$ & 0.8 \\
Gestational age in weeks (mean \pm SD) & $30.4 \pm 5.2$ & $30.6 \pm 4.8$ & 0.12 \\
Prematurity (gestational age <36 weeks) (\%) & $47(52.8)$ & $1140(70.5)$ \\
\hline \multicolumn{2}{r}{} \\
\hline
\end{tabular}

Table 5 - Comparison of respiratory syncytial virus positivity among the 3 dosing regimens considered.

\begin{tabular}{lccc}
\hline Seasons & $\begin{array}{c}\text { RSV positivity } \\
\mathbf{n}(\%)\end{array}$ & $\begin{array}{c}\text { RSV negativity } \\
\mathbf{n ~ ( \% )}\end{array}$ & $P$-value \\
\hline 2009-2010 season ${ }^{1}$ & $10(11.2)$ & $160(11.3)$ & 0.17 \\
2010-2011 season ${ }^{2}$ & $15(16.9)$ & $149(10.5)$ & \\
Subsequent seasons ${ }^{3}$ & $64(71.9)$ & $1105(78.2)$ & \\
Total & $\mathbf{8 9}(100)$ & $1414(100)$ & \\
\hline \multicolumn{2}{r}{ 'Palivizumab dosing regimen: every 4 weeks starting in November, ${ }^{2}$ Palivizumab dosing } \\
regimen: every 4 weeks starting in mid-September, ${ }^{3}$ Palivizumab dosing regimen: every 3 \\
weeks starting in mid-September, RSV - respiratory syncytial virus \\
\hline
\end{tabular}

decreased by half with the new palivizumab dosing regimen, the difference between the considered groups was not significant. This result may be due to different factors: far fewer participants were included in the group dosed according to the product labeling $(\mathrm{n}=170)$ and the early injection group $(\mathrm{n}=164)$ than in the new dosing regimen group $(n=1169)$, the baseline characteristics of each group were not comparable, and the incidence rate may vary from season to season due to climate conditions (mild or extremely cold winter).

Respiratory syncytial virus infection places a large disease burden on Saudi children, despite recent decreases in infection rates. As it is done at the RSV prophylaxis center, future efforts must focus on improving sanitation and awareness within families and medical staff about ways to limit spread, as these measures will likely be important for further improving health outcomes. It will be imperative to continue to observe seasonal changes and administer prophylaxis based on local surveillance to ensure the appropriate use of palivizumab. Expanding dosing regimen of palivizumab in young children may decrease further infection rates but a structured cost-effectiveness analysis is required to allow solid conclusions.
Acknowledgment. The author gratefully acknowledge the medical students, nurses, and medical assistants at the Pediatric Pulmonary Medicine Department, Prince Sultan Military Medical City, Riyadh, Saudi Arabia for their efforts. We would also like to thank Wiley Editing Services for English language editing.

\section{References}

1. Nair H, Nokes DJ, Gessner BD, Dherani M, Madhi SA, Singleton RJ, et al. Global burden of acute lower respiratory infections due to respiratory syncytial virus in young children: a systematic review and meta-analysis. Lancet 2010; 375: 1545-1555.

2. Lozano R, Naghavi M, Foreman K, Lim S, Shibuya K, Aboyans $\mathrm{V}$, et al. Global and regional mortality from 235 causes of death for 20 age groups in 1990 and 2010: a systematic analysis for the Global Burden of Disease Study 2010. Lancet 2012; 380: 2095-2128.

3. Turner TL, Kopp BT, Paul G, Landgrave LC, Hayes D Jr, Thompson R. Respiratory syncytial virus: current and emerging treatment options. Clinicoecon Outcomes Res 2014; 6: 217-225.

4. Langley GF, Anderson LJ. Epidemiology and prevention of respiratory syncytial virus infections among infants and young children. Pediatr Infect Dis J 2011; 30: 510-517.

5. Glezen WP, Taber LH, Frank AL, Kasel JA. Risk of primary infection and reinfection with respiratory syncytial virus. Am J Dis Child 1986; 140: 543-546. 
6. Kudhari P, Brosio F, Malaventura C, Stefanati A, Orsi A, Icardi $\mathrm{G}$, et al. Human respiratory syncytial virus and hospitalization in young children in Italy. Italian J Pediatrics 2018; 44: 50.

7. Régnier SA, Huels J. Association between respiratory syncytial virus hospitalizations in infants and respiratory sequelae: systematic review and meta-analysis. J. Pediatr Infect Dis J. 2013; 32: 820-826.

8. Bakir TM, Halwani M, Ramia S. Viral aetiology and epidemiology of acute respiratory infections in hospitalized Saudi children. J Trop Pediatr 1998; 44: 100-103.

9. Shay DK, Holman RC, Newman RD, Lui LL, Stout JW, Anderson LJ. Bronchiolitis-associated hospitalizations among US children, 1980-1996. JAMA 1999; 282: 1440-1446.

10. Ralston SL, Lieberthal AS, Meissner HC, Baley JE, Gadomski AM, Johnson DW, et al. Clinical practice guideline: the diagnosis, management, and prevention of bronchiolitis. Pediatrics 2014; 134: e1474-e1502.

11. Akhter J, Al Johani S. Epidemiology and Diagnosis of Human Respiratory Syncytial Virus Infections. In: Resch B, editor. Human Respiratory Syncytial Virus Infection. Rijeka (HR): InTech Europe; 2011. p. 161-176.

12. Huang K, Incognito L, Cheng X, Nancy D, Wu U, Wu H. Respiratory syncytial virus-neutralizing monoclonal antibodies motavizumab and palivizumab inhibit fusion. J Virol 2010; 84: 8132-8140.

13. Prevention of respiratory syncytial virus infections: indications for the use of palivizumab and update on the use of RSV-IGIV. American Academy of Pediatrics Committee on Infectious Diseases and Committee of Fetus and Newborn. Pediatrics 1998; 102: 1211-1216.

14. American Academy of Pediatrics. In: Pickering LK, Baker CJ, Kimberlin DW, Long SS, editors. Red Book: 2012 Report of the Committee on Infectious Diseases. 29th ed. Elk Grove Village, IL: American Academy of Pediatrics; 20012. p. 609.

15. American Academy of Pediatrics Committee on Infectious Diseases, American Academy of Pediatrics Bronchiolitis Guidelines Committee. Updated guidance for palivizumab prophylaxis among infants and young children at increased risk of hospitalization for respiratory syncytial virus infection. Pediatrics 2014; 134: 415-420.
16. Palivizumab, a humanized respiratory syncytial virus monoclonal antibody, reduces hospitalization from respiratory syncytial virus infection in highrisk infants. The IMpact-RSV Study Group. Pediatrics 1998; 102: 531-537.

17. Hall CB, Weinberg GA, Blumkin AK, Edwards KM, Staat MA, Schultz AF, et al. Respiratory syncytial virus-associated hospitalizations among children less than 24 months of age. Pediatrics 2013; 132: e341-e348.

18. Stevens TP, Sinkin RA, Hall CB, Maniscalco WM, McConnochie KM. Respiratory syncytial virus and premature infants born at 32 weeks' gestation or earlier: hospitalization and economic implications of prophylaxis. Arch PediatrAdolesc Med 2000; 154: 55-61.

19. Boyce TG, Mellen BG, Mitchel EF Jr, Wright PF, Griffin MR. Rates of hospitalization for respiratory syncytial virus infection among children in medicaid. J Pediatr 2000; 137: 865-870.

20. Winterstein AG, Knox CA, Kubilis P, Hampp C. Appropriateness of age thresholds for respiratory syncytial virus immunoprophylaxis in moderate-preterm infants: a cohort study. JAMA Pediatr 2013; 167: 1118-1124.

21. Feltes TF, Cabalka AK, Meissner HC, Piazza FM, Carlin DA, Top FH Jr, et al. Palivizumab prophylaxis reduces hospitalization due to respiratory syncytial virus in young children with hemodynamically significant congenital heart disease. J Pediatr 2003; 143: 532-540.

22. Chang RK, Chen AY. Impact of palivizumab on RSV hospitalizations for children with hemodynamically significant congenital heart disease. PediatrCardiol 2010; 31: 90-95.

23. Bodenhetmer T. Disease management - promises and pitfalls. $N$ Engl J Med 1999; 340: 1202-1205.

24. Bont L, Checchia PA, Fauroux B, Figueras-Aloy J, Manzoni P, Paes B, et al. Defining the epidemiology and burden of severe respiratory syncytial virus infection among infants and children in western countries. Infect Dis Ther 2016; 5: 271-298. 